\title{
DIAGNOSTIC ACCURACY OF SQUASH SMEAR TECHNIQUE IN BRAIN TUMORS
}

Sanjay Kumar Nigam, Nilam Nigam, Anand Mishra

1. Associate Professor, Department of Pathology, Rama Medical College Hospital \& Research Centre, Mandhana Kanpur, U.P.

2. Associate Professor, Department of Pharmacology, Rama Medical College Hospital \& Research Centre, Mandhana Kanpur, U.P.

3. Associate Professor, Department of Biochemistry, Rama Medical College Hospital \& Research Centre, Mandhana Kanpur, U.P.

\section{CORRESPONDING AUTHOR}

Dr. Sanjay Kumar Nigam, House no. 308, Rama Medical College,

Mandhana, Kanpur, 209217.

E-mail: sknigam@yahoo.com Ph: 00919411918206.

ABSTRACT: Background \& Objectives: Primary tumors of central nervous system constitute less than $2 \%$ of overall human cancers in adults however; they constitute second most common frequently encountered tumors in children after leukaemia. Use of smear technique has been described for many years on specimens obtained with stereotactic devices, which allow multiple sampling for the diagnosis of deep seated lesions. Squash smear technique saves time and amount of tissue needed. METHODS: A total of 75 cases of intracranial space occupying lesions were studied. The squash smear technique was used to diagnose the brain Tumors and was compared with histopathological examination of same tumor. RESULTS: Out of 75 cases in 8 $(10.7 \%)$ cases discordance was observed between squash smear diagnosis and histologic diagnosis. In $67(89.3 \%)$ cases squash smear diagnosis was in accordance with the final histologic diagnosis. Thus the diagnostic accuracy of squash smear technique in this study is 89.3\%. INTERPRETATION \& CONCLUSIONS: Thus the value of squash smear technique in rapid preoperative diagnosis of neurosurgical biopsies is corroborated by above study and the accuracy of this study matched with the other studies done in the past on squash smear technique and it should be used regularly for rapid intra-operative diagnosis of intracranial space occupying lesion.

KEY WORDS: squash smear technique, intracranial space occupying lesions, histopathological examination.

INTRODUCTION: Primary tumors of central nervous system constitute less than $2 \%$ of overall human cancers in adults however; they constitute second most common frequently encountered Tumors in children after leukaemia. (1)

As the biological behaviour or prognosis is partly dependent on the constituent cell type, it is of utmost important to classify these tumors. Equally important is to recognize certain primary brain tumors, which respond to aggressive radiotherapy or chemotherapy. Rapid preoperative diagnosis is of immense value to select treatment options. $(2,3)$

Clinical diagnosis has improved with the advent of high resolution imaging techniques. However a definite diagnosis can only be obtained by cytological or histopathological examination of the tumor tissue. Use of smear technique has been described for many years on specimens obtained with stereotactic devices, which allow multiple sampling for the diagnosis 
of deep seated lesions. The technique is also helpful to identify various non neoplastic space occupying lesions and radiation induced necrosis versus recurrent Tumors. (4)

\section{ADVANTAGES OF SQUASH SMEAR PREPARATIONS -}

The economy of time and amount of tissue needed. (5)

There is better preservation of cellular details.

The background of smear may contribute valuable information about the nature of a tumour.

DISADVANTAGES OF SMEAR PREPARATION -

Loss of cyto-architectural details.

Vascular tumors where stromal componen resist squashing.

Difficulties in grading the tumors.

\section{AIMS AND OBJECTIVES-}

To provide rapid diagnosis of central nervous system tumors.

To evaluate the diagnostic accuracy of squash smear technique.

MATERIAL AND METHODS: Present study was conducted in the pathology department of Rama Medical College and Hospital Research Centre Mandhana Kanpur on patients admitted in the department of surgery. A total of 75 cases of intracranial space occupying lesions were studied.

In every case age, sex, clinical history, duration of illness, findings on smear examination, radiological findings (CT/MRI) and operative notes were recorded.

METHODS OF PREPARING SQUASH SMEARS: Unfixed tissue in normal saline was taken from O.T. Small bits of tissue about 1-2 $\mathrm{mm}$ in size were selected and squashed between the two glass slides and smears prepared. (6)

Smears were fixed in absolute alcohol for 2 minutes, washed in water for one minute and stained with Harri's hematoxylin for five minutes. Smears were kept in $0.5 \%$ aqueous hydrochloride for ten to twenty seconds and rinsed in water for two minutes. Finally smears were stained with eosin and washed in absolute alcohol, dried and then mounted in DPX.

Depending upon the cyto-morphological features, in squash smears, the cyto-diagnosis of all cases was recorded in a predesigned proforma.

Histological sections were evaluated and final histological diagnosis was recorded in a predesigned proforma. Both cytologic (squash smears) diagnosis and final histopathologic diagnosis were compared to assess the diagnostic accuracy of squash smears in central nervous system Tumors. Special stains were used as and when required. During the entire study need for Immunohistochemical stains or cytogenetics study was not felt.

OBSERVATIONS AND RESULTS: In the present study role of the squash smear technique in the diagnosis of central nervous tumors and its correlation with histopathology has been evaluated. A total of 75 cases of central nervous system tumors attending surgery department during the period of one year at Rama Medical College and Hospital Research Centre Mandhana Kanpur 
U.P. were selected for this study. Of these cases, 72 (96\%) were intracranial space occupying lesions and $3(4 \%)$ were spinal lesions.

AGE AND SEX DISTRIBUTION- (TABLE 1): Peak incidence of brain Tumors was observed in middle life and they comprised 17 (22.7\%) of tumors examined. Second peak was observed in second decade of life and male / female ratio was 5.5:1. Male/female ratio of all patients irrespective of age group was 2.12:1. Age of youngest patient was 5 months. Age of the oldest patient was 75 years.

Table-1 age and sex distribution of patients $(n=75)$

\begin{tabular}{|l|l|l|l|l|}
\hline $\begin{array}{l}\text { Age distribution } \\
\text { (years) }\end{array}$ & $\begin{array}{l}\text { No. Of } \\
\text { cases. }\end{array}$ & $\mathbf{\%}$ & Male & Female \\
\hline$<10$ & 05 & 6.6 & 01 & 04 \\
\hline $11-20$ & 13 & 17.3 & 11 & 02 \\
\hline $21-30$ & 09 & 12.0 & 05 & 04 \\
\hline $31-40$ & 15 & 20.0 & 11 & 04 \\
\hline $41-50$ & 17 & 22.7 & 12 & 05 \\
\hline $51-60$ & 10 & 13.3 & 07 & 03 \\
\hline $61-70$ & 04 & 5.3 & 03 & 01 \\
\hline$>70$ & 02 & 2.6 & 01 & 01 \\
\hline & & & 51 & 24 \\
\hline
\end{tabular}

Following lesions were diagnosed by examining morphology of individual lesion on squash smears - as shown in table No. 2

Astrocytoma, Oligodendroglioma, Ependymoma, Pituitary adenoma, Medullobalstoma, Meningioma, Schwannoma, Neurocytoma, Craniopharyngioma, Lymphoma, Metastatic carcinoma and Epidermoid cyst. Though heamangioblastomas were difficult to squash because of hemorrhage and fibrosis hence on squash smears a diagnosis of benign mesenchymal tumor was given.

Table 2 Cytological evaluation of squash smears - $(n=75)$ 
ORIGINAL ARTICLE

\begin{tabular}{|c|c|c|}
\hline Diagnosis of squash smears & No. Of cases & $\%$ \\
\hline Astrocytoma low grade & 12 & 16.0 \\
\hline Malignant glioma & 13 & 17.3 \\
\hline Oligodendroglioma & 01 & 1.3 \\
\hline Ependymoma & 01 & 1.3 \\
\hline Pituitary adenoma & 03 & 4.0 \\
\hline Medullobalstoma & 08 & 10.7 \\
\hline Neurocytoma & 01 & 1.3 \\
\hline Meningioma & 16 & 21.3 \\
\hline Schwannoma & 09 & 12.0 \\
\hline Craniopharyngioma & 02 & 2.6 \\
\hline Benign mesenchymal tumor & 03 & 4.0 \\
\hline Small round cell tumor & 01 & 1.3 \\
\hline Lymphoma & 01 & 1.3 \\
\hline Metastasis & 01 & 1.3 \\
\hline Epidermoid cyst & 03 & 4.0 \\
\hline
\end{tabular}

Histopathological evaluation of biopsies from 75 cases revealed that $21(28.0 \%)$ cases had morphological features of astrocytomas (low grade and high grade), of which 8 were grade II astrocytomas, 2 were grade III astrocytoma and 11 were glioblastoma. In 2 (2.6\%) cases diagnosis of oligodendroglioma was given, In 2 (2.6\%) cases diagnosis of ependymoma was given, In $16(21.3 \%)$ cases diagnosis of meningioma was given, in 9 (12\%) cases diagnosis of Schwannoma was given, in $8(10.7 \%)$ cases diagnosis of Medullobalstoma was given, in 3 $(4.0 \%)$ cases diagnosis of pituitary adenoma was given, and in $2(2.6 \%)$ cases diagnosis of Craniopharyngioma was given. In 3 (4.0\%) cases diagnosis of hemangioblastoma was given, and in $3(4.0 \%)$ cases diagnosis of Epidermoid cyst was given. One case each from oligoastrocytoma, neurocytoma, anaplastic oligodendroglioma, paraganglioma, lymphoma and metastatic carcinoma was recorded. 
Table - 3 Histopathological evaluation of lesions $(n=75)$ -

\begin{tabular}{|c|c|c|}
\hline Histopathological diagnosis & No. Of cases & $\%$ \\
\hline Astrocytoma grade II & 08 & 10.7 \\
\hline Astrocytoma grade III & 02 & 2.6 \\
\hline Glioblastoma & 11 & 14.7 \\
\hline Mixed oligo astrocytoma & 01 & 1.3 \\
\hline Oligodendroglioma & 02 & 2.6 \\
\hline Anaplastic oligodendroglioma & 01 & 1.3 \\
\hline Ependymoma & 02 & 2.6 \\
\hline Neurocytoma & 01 & 1.3 \\
\hline Pituitary adenoma & 03 & 04 \\
\hline Medullobalstoma & 08 & 10.7 \\
\hline Meningioma & 16 & 21.3 \\
\hline Schwannoma & 09 & 12.0 \\
\hline Craniopharyngioma & 02 & 2.6 \\
\hline Paraganglioma & 01 & 1.3 \\
\hline Hemangioblastoma & 03 & 4.0 \\
\hline Lymphoma & 01 & 1.3 \\
\hline Metastatic carcinoma & 01 & 1.3 \\
\hline Epidermoid cyst & 03 & 4.0 \\
\hline
\end{tabular}

Of these 75 cases, $8(10.7 \%)$ cases showed discordant findings on cytologic and histological examination. Of these, 3 cases were diagnosed as low grade astrocytoma on squash smears, were subsequently diagnosed as ependymoma, mixed oligoastrocytoma and oligo dendroglioma on histological examination where as one case was diagnosed as malignant glioma on squash smears and was subsequently diagnosed as anaplastic oligodendroglioma on histologic examination.

In three cases diagnosis of benign mesenchymal tumor was given on squash smears and final histologic diagnosis of hemangioblastoma was given in all 3 cases.

In one case diagnosis of small round cell tumor was given on squash smears and final histologic diagnosis of paraganglioma was given. 
In rest of the other tumors like pituitary adenoma, medulloblastoma, meningioma, schwannoma, craniopharyngioma, neurocytoma, lymphoma, and metastatic carcinoma cytologic (squash smear diagnosis) was in accordance with the final histologic diagnosis.

In $8(10.7 \%)$ cases discordance was observed between squash smear diagnosis and histologic diagnosis. In 67 (89.3\%) cases squash smear diagnosis was in accordance with the final histologic diagnosis. Thus the diagnostic accuracy of squash smear technique in this study is $89.3 \%$.

Table - 4 comparative analysis of cytologic and histologic diagnosis

\begin{tabular}{|c|c|c|c|}
\hline Diagnosis & $\begin{array}{c}\text { Squash smear } \\
\text { diagnosis }\end{array}$ & $\begin{array}{c}\text { Histopathologica } \\
\text { I diagnosis }\end{array}$ & $\%$ accuracy \\
\hline Astrocytoma & 25 & 21 & 84 \\
\hline Oligodendroglioma & 01 & 03 & 33.3 \\
\hline Ependymoma & 01 & 02 & 50 \\
\hline Oligoastrocytoma & - & 01 & - \\
\hline Neurocytoma & 01 & 01 & 100 \\
\hline Pituitary adenoma & 03 & 03 & 100 \\
\hline Medulloblastoma & 08 & 08 & 100 \\
\hline Meningioma & 16 & 16 & 100 \\
\hline Schwannoma & 09 & 09 & 100 \\
\hline Craniopharyngioma & 02 & 02 & 100 \\
\hline Paraganglioma & - & 01 & - \\
\hline Hemangioblastoma & - & 03 & - \\
\hline Lymphoma & 01 & 01 & 100 \\
\hline Metastatic carcinoma & 01 & 01 & 100 \\
\hline Epidermoid cyst & 03 & 03 & 100 \\
\hline
\end{tabular}

Table -5 discordant results ( 8 cases) Squash smear diagnosis Final histologic diagnosis 


\section{ORIGINAL ARTICLE}

\begin{tabular}{|l|l|}
\hline Low grade astrocytoma & Ependymoma \\
\hline Low grade astrocytoma & Mixed oligoastrocytoma \\
\hline Low grade astrocytoma & Oligodendroglioma \\
\hline Malignant glioma & Anaplastic oligodendroglioma \\
\hline Small round cell tumor & Paraganglioma \\
\hline Benign mesenchymal tumor (3 cases) & hemangioblastoma \\
\hline
\end{tabular}

DISCUSSION: The intra-operative cytology preparation was first introduced by Eisenhardt L in 1930 and by Badt in 1937. (7)

Present work has been undertaken to study the diagnostic accuracy of squash smear technique for rapid per-operative diagnosis of neurosurgical biopsies. A total of 75 lesions were examined in this study. In all cases history, laboratory investigations, radiological findings and previous investigation if any were recorded. Biopsy material was obtained by craniotomy from these cases intra-operatively and was subjected to squash smear technique followed by subsequent histopathological examination of the remaining material. (8)

This study showed that peak incidence of brain Tumors was in the middle life and they constituted $17(22.7 \%)$ of all the Tumors examined with Second peak in $2^{\text {nd }}$ decade of life and male/female ratio was 5.5:1 in this age group. Age of the youngest patient was 5 months old baby and age of the oldest was 75 years. Male/female ratio of all patients irrespective of age group was 2.12:1. Thus male showed a greater incidence of brain Tumors as compared to females. (9)

In the present study, accuracy rate of $89.3 \%$ is comparable to the other studies conducted in the past. $(10,11,12,13,14,15)$

CONCLUSION: Thus the value of squash smear technique in rapid preoperative diagnosis of neurosurgical biopsies is corroborated by above study. The accuracy of this study (89.3\%) matched with the other studies done in the past on squash smear technique. So we recommend using this technique regularly for rapid intra-operative diagnosis of intracranial space occupying lesion. $(10,11,12,13,14,15)$

\section{BIBLIOGRAPHY:}

1. Lannering B, Sandström PE, Holm S, Lundgren J, Pfeifer S, Samuelsson U, Strömberg B, Gustafsson G; Swedish Childhood CNS Tumor Working Group Classification, incidence and survival analyses of children with CNS Tumors diagnosed in Sweden 1984-2005. Acta Paediatr. 2009 Oct;98(10):1620-7. Epub 2009 Jul 7.

2. (2). Asha T, Shankar SK, Rao TV, Das S. Role of squash-smear technique for rapid diagnosis of neurosurgical biopsies--a cytomorphological evaluation. Indian J Pathol Microbiol. 1989 Jul;32(3):152-60.

3. (3)N. Krishnani, N. Kumari, S. Behari, C. Rana and P. Gupta Intraoperative squash cytology: diagnostic accuracy and its impact on immediate surgical management of 
central nervous system Tumors Cytopathology. 2011 Aug 15. doi: 10.1111/j.13652303.2011.00905.x.

4. Collaço LM, Tani E, Lindblom I, Skoog L. Stereotactic biopsy and cytological diagnosis in solid and cystic intracranial lesions. Cytopathology. 2003;14:131-5.

5. Olasode BJ, Ironside JW. The brain smear, a rapid affordable intraoperative diagnostic technique for brain Tumors appropriate for Africa. Trop Doct. 2004;34:223-5.

6. Silverberg SG, Delellis RA, Frable WJ: Principle and practice of surgical pathology and cytopathology, vol.3, $3^{\text {rd }}$ edn.1997.

7. Eisenhardt L Cushing H. Diagnosis of Intracranial Tumors by Supravital Technique. Am I Pathol. 1930 Sep;6(5):541-552.7.

8. Nandita Ghosal, A S Hegde Ganesh Murthy, Sunil V Furtado Smear preparation of intracranial lesions: a retrospective study of 306 cases Diagnostic Cytopathology (impact factor: 1.3). 08/2011; 39(8):582-92.

9. Shibui S. The present status and trend of brain tumors based on the data of the Brain Tumor Registry of Japan. Brain Nerve. 2012 Mar;64(3):286-90.

10. Willems JG, Alva-Willems JM. Accuracy of cytologic diagnosis of central nervous system neoplasms in sterotactic biopsies. Acta Cytol. 1984 May-Jun;28(3):243-9.

11. Mc Mennemey WH: An appraisal of smear diagnosis in neurosurgery. Am. J. Clin. Pathol. $33: 471,1960$

12. Berkeley BB, Adams JH, Doyle D, Graham DI, Harper CG. The smear technique in the diagnosis of neurosurgical biopsies. N Z Med I. 1978 Jan 11;87(603):12-5.

13. Iqbal M, Shah A, Wani MA, Kirmani A, Ramzan A. Utility of Crush Smear Cytology in Intraoperative Diagnosis of Central Nervous System lesions. Acta Cytol 2006; 50(6): 608-16.

14. Shukla K, Parikh B, Shukla J, Trivedi P, Shah B. Accuracy of cytologic diagnosis of Central Nervous system Tumors in crush preparation. Indian J Pathol Microbiol. 2006;49:483-6.

15. Roessler K, Dietrich W, Kitz K. High diagnostic accuracy of cytologic smears of central nervous system Tumors. A 15-year experience based on 4,172 patients. Acta Cytol. 2002; 46:667-74. 